\title{
MS trailblazer on the art of medicine
}

$\mathrm{T}$

wo decades have passed since Dr. Thomas John "Jock" Murray began crafting the internationally acclaimed medical humanities program at Dalhousie University in Halifax, Nova Scotia.

Now, as medicine becomes increasingly specialized, and time with patients increasingly scarce, the role of the arts as a window into the human condition is more vital than ever, he says. "If you want to understand how people feel, you get that from literature, poetry and art."

The art of medicine was an early passion for Murray: "teachers thought I should do medical art, but I didn't have much originality as an artist," he quips.

Instead, the Pictou, Nova Scotia-native earned his medical degree at Dalhousie in 1963. Following two years in general practice, Murray trained in internal medicine, then in neurology in Halifax, London (Ontario) and Toronto before joining the Dalhousie medical faculty in 1970. There, he founded and directed the Dalhousie Multiple Sclerosis Research Unit at a time when few researchers or physicians were interested in the disease. He was also founder and president of the International Consortium of MS Centers - a group started by five friends that now has some 2000 members.

"Patients felt abandoned. Nobody wanted to see MS patients back in the early 70s because there was nothing they could offer in terms of treatment," Murray explains. "I didn't have anything particular to offer, but at least we could show we were interested by setting up a research program and taking care of their symptoms."

It became clear to Murray that medical education was discouraging physicians from tackling problems for which they didn't have answers. "The training

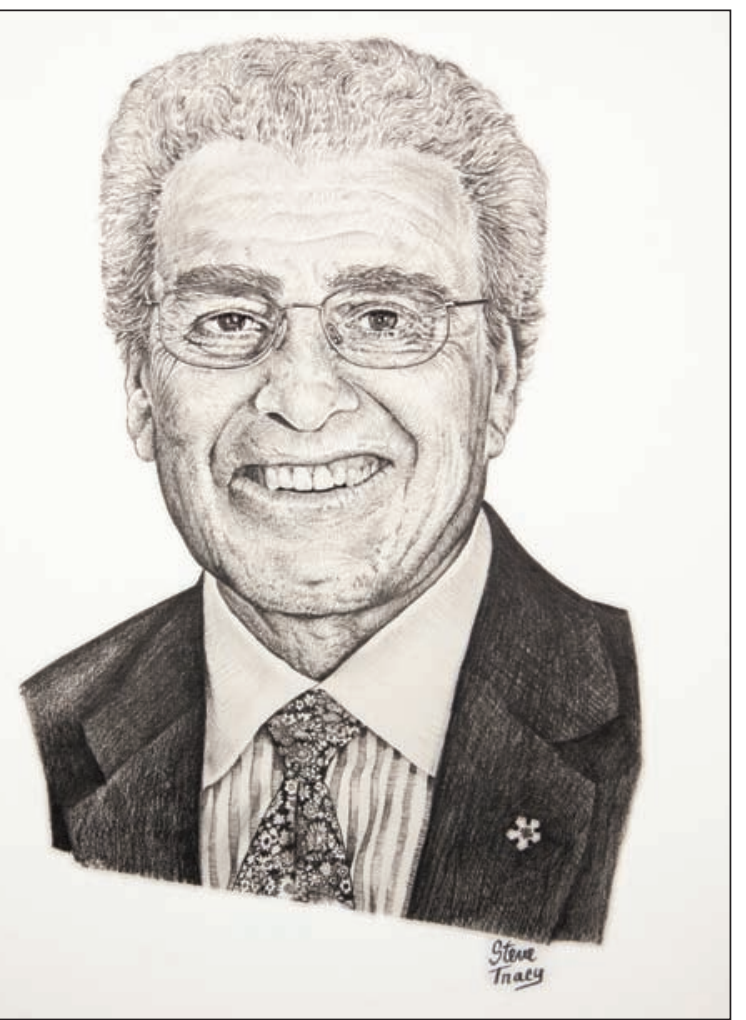

$C M A J$ has a conversation with Dr. Jock Murray, a leading international expert on multiple sclerosis and longtime champion of medical humanities. of physicians in modern medicine largely has been about the cure; if people had a disease you couldn't cure, it was thought you couldn't help them, when really you can provide a lot of help just by being someone who cares and can answer their questions."

As dean of medicine at Dalhousie from 1985 to 1992, Murray introduced a new problem-based approach to undergraduate medical education that emphasized critical thinking over rote knowledge. This model has since become the norm across Canada.

A 2014 inductee to the Canadian Medical Hall of Fame, Murray joined $C M A J$ by phone to reflect on his legacy in the fields of multiple sclerosis, medical education and humanities.

CMAJ: What first drew you to MS, particularly when so few others were interested in the field?
Murray: I had some patients who had MS who said repeatedly there were a lot of cases in the area where they lived. In the course of studying that cluster, what I came away with was how alone they felt ... family doctors couldn't answer their questions, and because there were no treatments at the time, there were no return appointments.

CMAJ: When you first floated the idea of a research unit, was there pushback from colleagues?

Murray: Some weren't happy. They worried it would open the floodgates [and give the impression there was a cure.] But it turned out that patients' first questions weren't about a cure. It was, "What's going on in the research?" We could answer that.
CMAJ: How have you seen the field change since you established the unit?

Murray: At first we only had the ability to take care of people's symptoms, answer their questions and determine where they were in the disease - and they got confidence from that.

CMAJ: You also set up one of the first computerized patient databases in Canada...

Murray: Before most people had even turned on a computer! We didn't know what caused MS - it could be genetics or where they lived - so we set it up to track all the information we might want to know in the future and used it on every patient, at every visit. By the 90s, we had a curve to show how people did without therapy, so when the first treatments came out we could track the difference they made 
across a lot of variables. It changed the story from hopeless to hopeful.

CMAJ: When did you become interested in reshaping medical education?

Murray: From caring for patients. ... If you get into a problem or have questions in your own practice, you can't say, "Someone give me a lecture." I also saw that we teach a lot about the mechanism of the body, but not about the human condition.

CMAJ: You've called the historic tension between the humanities and sciences a false dichotomy...

Murray: We know when a doctor sees a patient, it's not just about the doctor's ability to make a diagnosis or deliver a treatment; it's also about how the patient feels, who they are and what they value. Everyone agrees that physicians should have this broad understanding ... but we only teach the science, taking it for granted that they'll also turn out to be ethical and compassionate.

CMAJ: Have you seen that attitude change in recent years?

Murray: The real difficulty now is that medical schools want more humanities, but don't know how to do it, allocate time or budget for it. I think it will come down to gentle persuasion and infiltration people who want to see this happen involving themselves in curriculum development, using it in their practice, writing in medical journals - to bring the humanities into the fabric of medicine.

CMAJ: What are some small ways you do this?

Murray: One simple thing I use with MS patients is drawing aspects of the nervous system as I'm talking with them. They're only going to hear a certain amount, so I write and draw and at the end give them the paper. A lot of my teaching is also done using art — for example, explaining 18th century medicine as illustrated by [painter] William Hogarth.

CMAJ: Where do you think medical education needs to grow next?

Murray: The next challenge will be developing a distinct sense of social responsibility. Medical education is more than training for a high-earning job, and schools are starting to see themselves as more than isolated institutions. Now they're expected to address social progress and things happening in their own communities.

CMAJ: What advice would you give to young physicians?

Murray: The joys and rewards of medicine have not changed; despite changes in technology and the rest, it all comes down to time and relationships with patients. - Lauren Vogel, CMAJ

CMAJ 2015. DOI:10.1503/cmaj.109-4971 